\title{
A Renal Impairment Subgroup Analysis of the Safety and Efficacy of Naldemedine for the Treatment of Opioid-Induced Constipation in Patients with Chronic Non-Cancer Pain Receiving Opioid Therapy
}

This article was published in the following Dove Press journal:

Journal of Pain Research

\section{Lynn R Webster (D) \\ Martin E Hale ${ }^{2}$ \\ Tadaaki Yamada ${ }^{3}$ \\ James E Wild ${ }^{4}$}

'PRA Health Sciences, Salt Lake City, UT, USA; ${ }^{2}$ Gold Coast Research LLC, Plantation, FL, USA; ${ }^{3}$ Shionogi, Inc., Florham Park, NJ, USA; ${ }^{4}$ Upstate Clinical Research Associates, Williamsville, NY, USA
Correspondence: Lynn R Webster PRA Health Sciences, Salt Lake City, UT, USA

$\mathrm{Tel}+\mid$ 80I 269-8200

Email Irwebstermd@gmail.com
Purpose: Naldemedine, an oral, peripherally acting $\mu$-opioid receptor antagonist approved for the treatment of opioid-induced constipation (OIC), is renally excreted. This subgroup analysis integrated data from 3 Phase 3 trials (COMPOSE-1, COMPOSE-2, COMPOSE-3) to evaluate the safety and efficacy of naldemedine in patients with renal impairment (RI).

Patients and Methods: Patients age 18-80 years with chronic non-cancer pain (CNCP) and OIC received oral naldemedine $0.2 \mathrm{mg}$ or placebo once daily. RI subgroups consisted of patients with normal function (baseline glomerular filtration rate $\geq 90 \mathrm{~mL} / \mathrm{min} / 1.73 \mathrm{~m}^{2}$ ), mild ( $\geq 60$ to $<90 \mathrm{~mL} / \mathrm{min} / 1.73 \mathrm{~m}^{2}$ ), and moderate ( $\geq 30$ to $<60 \mathrm{~mL} / \mathrm{min} / 1.73 \mathrm{~m}^{2}$ ) RI. Safety assessments based on $\leq 12$ weeks of treatment from all 3 studies included incidence of treatment-emergent adverse events (TEAEs). Efficacy was based on the proportion of responders in COMPOSE-1 and COMPOSE-2 only, defined as $\geq 3$ spontaneous bowel movements (SBMs)/week and $\mathrm{a} \geq 1$-SBM/week increase from baseline for $\geq 9$ of 12 weeks and $\geq 3$ of the last 4 weeks.

Results: In total, 2328 patients were included in this analysis. The incidence of TEAEs was similar in the naldemedine and placebo groups (overall, $47.1 \%$ vs $45.6 \%$; normal, $44.6 \%$ vs $43.6 \%$; mild RI, $49.0 \%$ vs $44.7 \%$; moderate RI, $46.6 \%$ vs $55.9 \%$ ). GI-related TEAEs occurred more frequently in the naldemedine group versus placebo (overall, $21.8 \%$ vs $13.8 \%$; normal, $21.6 \%$ vs $12.5 \%$; mild RI, $22.6 \%$ vs $14.7 \%$; moderate RI, $18.0 \%$ vs $14.2 \%$ ). A significantly greater proportion of patients in the naldemedine $0.2 \mathrm{mg}$ group were responders versus the placebo group (overall, $50.1 \%$ vs $34.1 \%, P<0.0001$; normal, $52.0 \%$ vs $39.3 \%$; mild RI, $48.3 \%$ vs $30.3 \%$; moderate RI, $52.5 \%$ vs $31.7 \%$ ).

Conclusion: This integrated analysis confirmed that OIC treatment with naldemedine $0.2 \mathrm{mg}$ was generally well tolerated and effective in patients with $\mathrm{CNCP}$ and mild or moderate RI. Safety and efficacy results were consistent with the overall population.

Clinicaltrials.gov Registration: COMPOSE-1: NCT01965158; COMPOSE-2: NCT01993940; COMPOSE-3: NCT01965652.

Keywords: opioid-related disorders, opioid analgesics, naldemedine, renal insufficiency, constipation; chemically induced

\section{Plain Language Summary}

Opioid analgesic therapy is one treatment option for chronic moderate-to-severe cancer and non-cancer pain in selected patients. However, opioid-induced constipation is one of the most common side effects of opioid analgesic therapy. Naldemedine is approved in the United States, Japan, and the European Union for the treatment of opioid-induced 
constipation. Individuals with chronic conditions such as kidney disease may not be able to break down certain medications once in the body. As a result, there can be an impact on safety, efficacy, and dosing requirements for these drugs. This analysis determined the safety and efficacy of naldemedine $0.2 \mathrm{mg}$ once daily compared with placebo for up to 12 weeks based on a combined analysis of the COMPOSE-1, COMPOSE-2, and COMPOSE-3 studies in patients with renal impairment. The results of this analysis confirm that naldemedine dose adjustments are not needed in patients with renal impairment. The results also support the consistent safety and efficacy of naldemedine in the treatment of opioid-induced constipation.

\section{Introduction}

One common treatment option for chronic moderate-tosevere non-cancer and cancer pain in selected patients is opioid analgesic therapy. ${ }^{1}$ However, opioids are associated with a number of adverse effects, particularly opioidinduced bowel dysfunction. One of the most common symptoms is opioid-induced constipation (OIC), which results from the activation of $\mu$-opioid receptors that are distributed extensively throughout the enteric nervous system in the gastrointestinal (GI) tract. ${ }^{2}$ Unlike other adverse effects associated with opioid therapy, OIC persists unabated over time and can have a varying response to the use of laxatives. $^{2,3}$ Notably, patients may skip or reduce their opioid doses in an attempt to manage side effects such as OIC, which can lead to inadequate pain relief. ${ }^{3,4}$

Naldemedine is an oral, once-daily, peripherally acting $\mu$ opioid receptor antagonist (PAMORA) approved in Japan, the United States (US), and the European Union for treatment of OIC in adults. ${ }^{5-7}$ In the US, its efficacy and safety in this population were established in 2 identically designed 12week, Phase 3, placebo-controlled studies (COMPOSE-1 and COMPOSE-2) ${ }^{8}$ and a 52-week, Phase 3, placebocontrolled study (COMPOSE-3). ${ }^{9}$

Recent estimates indicate that approximately 1 in 7 Americans have chronic kidney disease. ${ }^{10}$ Comorbid kidney disease may affect the metabolism of certain drugs, which can influence dosing requirements; inappropriate dosing can increase the risk of adverse events or have an effect on efficacy. ${ }^{11}$ Therefore, it is important to determine whether the safety and efficacy profile of a medication is affected by comorbid renal impairment (RI). The objective of this analysis was to characterize the safety and efficacy of naldemedine $0.2 \mathrm{mg}$ once daily versus placebo for up to 12 weeks based on an integrated analysis of results from COMPOSE-1, COMPOSE-2, and COMPOSE-3 in patients with RI.

\section{Materials and Methods}

COMPOSE-1 (NCT01965158; conducted from August 2013

to January 2015) and COMPOSE-2 (NCT01993940; conducted from November 2013 to June 2015) were multicenter, randomized, double-blind, placebo-controlled, parallelgroup, Phase 3 clinical studies designed to evaluate the efficacy and safety of naldemedine $0.2 \mathrm{mg}$ once daily over a 12-week treatment period in patients with OIC and chronic non-cancer pain (Figure 1). ${ }^{8}$ COMPOSE-3 (NCT01965652; conducted from September 2013 to January 2016) was a multicenter, randomized, double-blind, placebocontrolled, parallel-group, Phase 3 clinical study designed to evaluate the safety and efficacy of naldemedine $0.2 \mathrm{mg}$ once daily over a 52-week treatment period in patients with OIC and chronic non-cancer pain (Figure 1). ${ }^{9}$ For the purpose of integration, data included in this analysis were from first dose up to 12 weeks of treatment in all 3 studies and do not include events reported during the follow-up periods. All 3 studies had investigational sites in North America and Europe, and COMPOSE-3 also had sites in Africa and Asia Pacific. The studies were conducted in accordance with the Declaration of Helsinki and Good Clinical Practice guidelines, and approved by an Institutional Review Board or independent ethics committee at each site (See Supplementary Data). Written informed consent was provided by all patients.

Key eligibility criteria in all 3 studies included ages 18 to 80 years, inclusive, chronic non-cancer pain for $\geq 3$ months (treated with opioid analgesics for $\geq 3$ months in COMPOSE-1 and COMPOSE-2) and OIC, and receiving a stable opioid analgesic regimen with total daily dose $\geq 30 \mathrm{mg}$ oral morphine equivalent for $\geq 1$ month before screening. Eligibility based on laxative use varied between the 12-week and the 52-week studies. For COMPOSE-1 and 2, patients could not currently be using or had to be willing to discontinue laxatives, except for rescue laxative use. Patients in COMPOSE-3 could be on laxative regimen at screening and could remain on a stable laxative program throughout trial. The proportion of patients either on a routine laxative regimen (naldemedine, 50.2\%; placebo, 54.0\%) or not (naldemedine, 30.0\%; placebo, $29.5 \%$ ) was similar between treatment groups. Patients in all trials met the following criterion regarding OIC severity: experienced $\leq 4$ spontaneous bowel movements (SBMs) during the 14-consecutive-day qualifying period during screening, with $\leq 3$ SBMs in any 7-day period. Furthermore, patients in COMPOSE- 1 and 2 experienced $\geq 1$ of the following OIC symptoms with $\geq 25 \%$ of bowel movements: straining, hard or 


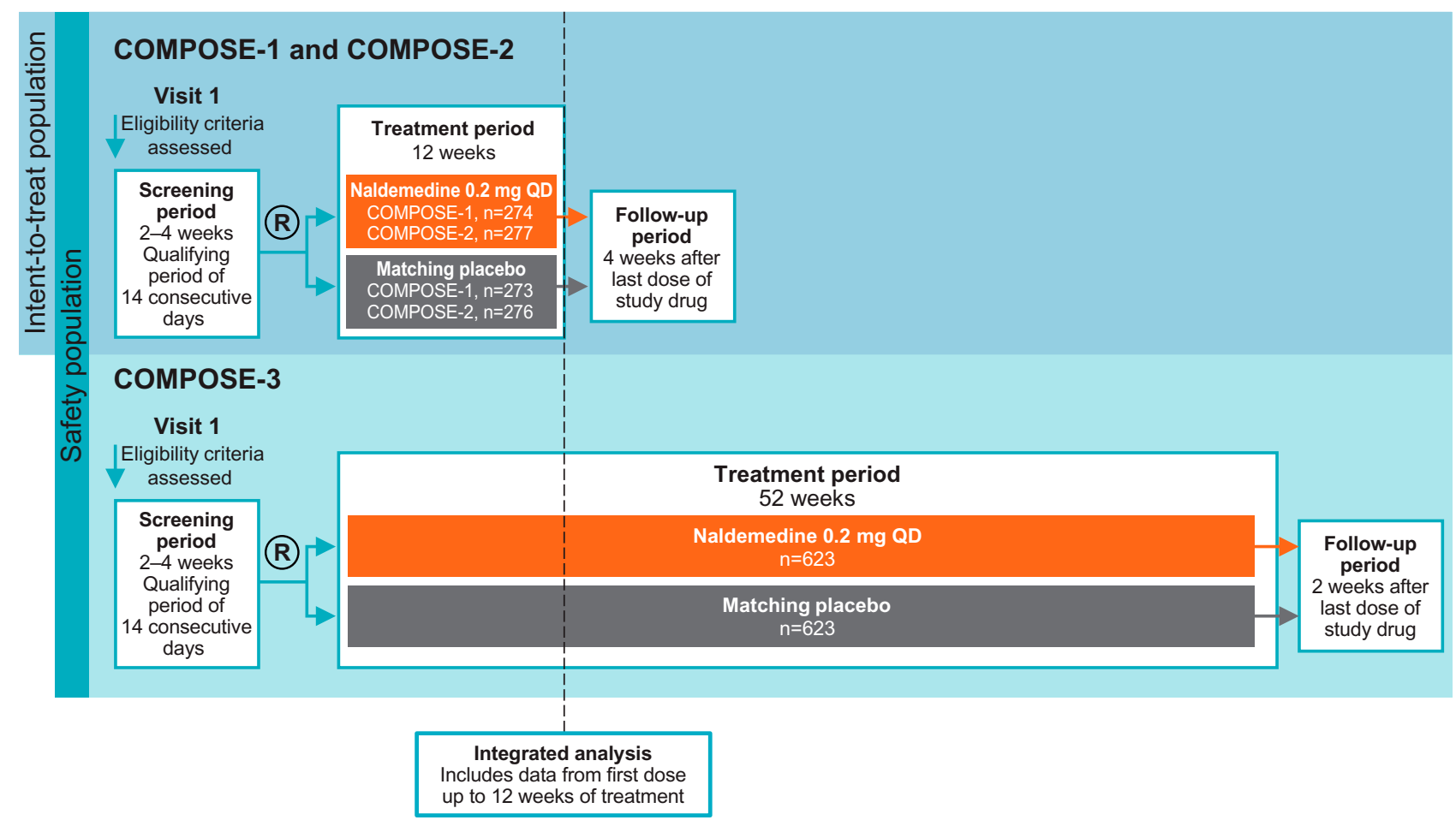

Figure I Study designs.

Abbreviation: $R$, randomization.

lumpy stools, sensation of incomplete evacuation, and sensation of anorectal obstruction/blockage. The key exclusion criteria were evidence/history of bowel structural abnormalities, strictures, obstructions, or history of bowel surgery, medical conditions affecting GI transit, history of chronic constipation unrelated to opioid use, and no history of previous laxative use for OIC.

Safety and tolerability assessments in the integrated analysis included data from all 3 studies (COMPOSE-1, COMPOSE-2, and COMPOSE-3) for up to 12 weeks (safety population), assessed by the incidence of treatment-emergent adverse events (TEAEs) and TEAEs in GI Disorders System Organ Class (SOC). The proportion of patients who experienced at least 1 TEAE of opioid withdrawal in the safety population was identified using the "drug withdrawal" standardized Medical Dictionary for Regulatory Activity query.

The safety population included all randomized patients who received at least one dose of study drug and were analyzed by the treatment actually received. The key efficacy assessment, based on data from the two 12-week studies (COMPOSE-1 and COMPOSE-2; intent-to-treat population, including all randomized patients), was the primary endpoint of proportion of responders. A responder was defined as having $\geq 3 \mathrm{SBMs} /$ week and $\mathrm{a} \geq 1 \mathrm{SBM} /$ week increase from baseline for $\geq 9$ of 12 weeks and $\geq 3$ of the last 4 weeks. Due to differences in the collection of efficacy assessments, COMPOSE-3 efficacy data were not included in this integrated analysis.

Data were analyzed for the overall population and by estimated glomerular filtration rate at baseline: $\geq 90 \mathrm{~mL} / \mathrm{min} /$ $1.73 \mathrm{~m}^{2}$ (normal); $\geq 60$ to $<90 \mathrm{~mL} / \mathrm{min} / 1.73 \mathrm{~m}^{2}$ (mild RI); and $\geq 30$ to $<60 \mathrm{~mL} / \mathrm{min} / 1.73 \mathrm{~m}^{2}$ (moderate RI). Data for patients with estimated glomerular filtration rate $<30 \mathrm{~mL} / \mathrm{min} / 1.73 \mathrm{~m}^{2}$ (severe RI) are not presented due to the small sample size $(n=3)$.

\section{Results \\ Safety}

In total, 2328 patients in the COMPOSE-1, COMPOSE-2, and COMPOSE-3 studies were included in the integrated safety population. Baseline demographics, opioid use, and RI severity for the safety population are shown in Table 1; characteristics were generally well matched between the naldemedine and placebo groups.

In the overall safety population, $47.1 \%$ of patients receiving naldemedine $0.2 \mathrm{mg}$ and $45.6 \%$ of patients receiving placebo reported TEAEs, with similar values reported across RI subgroups (Table 2); the most common 
Table I Baseline Demographics and Medical Characteristics (Integrated Safety and Intent-to-Treat Populations)

\begin{tabular}{|c|c|c|c|c|}
\hline \multirow[t]{2}{*}{ Attribute } & \multicolumn{2}{|c|}{$\begin{array}{l}\text { Safety Population (COMPOSE-I/ } \\
\text { COMPOSE-2/COMPOSE-3) }\end{array}$} & \multicolumn{2}{|c|}{$\begin{array}{l}\text { Intent-to-Treat Population } \\
\text { (COMPOSE-I/COMPOSE-2) }\end{array}$} \\
\hline & $\begin{array}{l}\text { Naldemedine } \\
0.2 \mathrm{mg} / \mathrm{day}(\mathrm{n}=1 \mathrm{l63})\end{array}$ & Placebo $(n=1165)$ & $\begin{array}{l}\text { Naldemedine } \\
0.2 \mathrm{mg} / \text { day }(\mathrm{n}=549)\end{array}$ & Placebo $(n=546)$ \\
\hline Mean age, years (SD) & $53.6(11.1)$ & $52.9(10.9)$ & $53.7(10.5)$ & $53.1(11.2)$ \\
\hline Female, \% (n) & $60.6(705)$ & $63.3(738)$ & $59.4(326)$ & $61.5(336)$ \\
\hline Mean BMI, kg/m² (SD) & $31.5(7.4)^{\mathrm{a}}$ & $31.4(7.4)^{\mathrm{a}}$ & $3 \mathrm{I} .4(7.2)$ & $31.3(7.2)$ \\
\hline \multicolumn{5}{|l|}{ Region, \% (n) } \\
\hline North America & $85.8(998)$ & $86.4(1007)$ & $85.8(47 I)$ & $85.7(468)$ \\
\hline Rest of world & $14.2(165)$ & $13.6(158)$ & $14.2(78)$ & $14.3(78)$ \\
\hline \multicolumn{5}{|l|}{ Race, \% (n) } \\
\hline White & $79.4(924)$ & $80.9(943)$ & $79.8(438)$ & $81.9(447)$ \\
\hline Black & $19.0(221)$ & $16.7(195)$ & $18.6(102)$ & $15.9(87)$ \\
\hline Other & $1.5(18)$ & $2.3(27)$ & $1.6(9)$ & $2.2(12)$ \\
\hline \multicolumn{5}{|l|}{ Opioid use } \\
\hline Mean duration of opioid use, months (SD) & $61.8(65.4)$ & $58.1(56.4)$ & $61.1(61.7)$ & $59.2(57.1)$ \\
\hline Mean daily opioid dose, MED, mg (SD) & $122.2(134.5)$ & 126.I (157.3) & $131.8(150.0)$ & $126.7(135.8)$ \\
\hline \multicolumn{5}{|l|}{ Patients with daily opioid dose, \% (n) } \\
\hline$<30 \mathrm{mg}$ & $1.4(16)$ & $1.2(14)$ & $1.1(6)$ & $0.5(3)$ \\
\hline 30 to $100 \mathrm{mg}$ & $59.1(687)$ & $58.2(678)$ & $56.8(3 \mid 2)$ & $56.6(309)$ \\
\hline$>100 \mathrm{mg}$ to $\leq 200 \mathrm{mg}$ & $23.0(268)$ & $24.4(284)$ & $25.3(139)$ & $24.7(135)$ \\
\hline$>200 \mathrm{mg}$ to $\leq 400 \mathrm{mg}$ & $12.6(147)$ & $11.5(134)$ & I3.| (72) & $13.4(73)$ \\
\hline$>400 \mathrm{mg}$ & $3.9(45)$ & $4.7(55)$ & $3.6(20)$ & $4.8(26)$ \\
\hline Mean duration of treatment exposure, days (SD) & $76.6(20.8)$ & $77.2(18.9)$ & $77.5(22.0)$ & $77.9(20.4)$ \\
\hline Mean eGFR ${ }^{b}, \mathrm{~mL} / \mathrm{min} / 1.73 \mathrm{~m}^{2}(\mathrm{SD})$ & $85.2(21.9)$ & $85.0(21.2)$ & $85.0(22.0)$ & $85.1(21.5)$ \\
\hline \multicolumn{5}{|l|}{ eGFR ${ }^{b}, \%(n)$} \\
\hline$\geq 90 \mathrm{~mL} / \mathrm{min} / 1.73 \mathrm{~m}^{2}$ (normal) & $37.4(435)$ & $39.7(463)$ & $35.7(196)$ & $40.1(219)$ \\
\hline$\geq 60$ to $<90 \mathrm{~mL} / \mathrm{min} / \mathrm{I} .73 \mathrm{~m}^{2}$ (mild RI) & $51.1(594)$ & $49.2(573)$ & $53.2(292)$ & $48.9(267)$ \\
\hline$\geq 30$ to $<60 \mathrm{~mL} / \mathrm{min} / \mathrm{l} .73 \mathrm{~m}^{2}$ (moderate $\mathrm{RI}$ ) & $11.4(133)$ & $10.9(127)$ & II.I (6I) & $11.0(60)$ \\
\hline$<30 \mathrm{~mL} / \mathrm{min} / \mathrm{l} .73 \mathrm{~m}^{2}(\text { severe } \mathrm{RI})^{\mathrm{c}}$ & $0.1(1)$ & $0.2(2)$ & $0(0)$ & $0(0)$ \\
\hline
\end{tabular}

Notes: ${ }^{a} \mathrm{n}=1162 .{ }^{b}$ Calculated by the Modification of Diet in Renal Disease equation. ${ }^{c}$ Patients with severe renal impairment are not included in safety or efficacy analyses due to small sample size.

Abbreviations: BMI, body mass index; eGFR, estimated glomerular filtration rate; MED, morphine equivalent dose; RI, renal impairment; SD, standard deviation.

TEAEs overall were abdominal pain, diarrhea, and nausea. TEAEs of GI Disorders SOC were reported in $21.8 \%$ of patients in the naldemedine $0.2 \mathrm{mg}$ group and $13.8 \%$ of patients in the placebo group; similar values were reported across the RI subgroups (Table 2). Likewise, the proportions of patients experiencing the specific GI-related TEAEs of abdominal pain, diarrhea, nausea, or vomiting were generally similar across RI subgroups and similar to the overall patient population, with slightly higher proportions in the naldemedine group than in the placebo group (Figure 2).

Nineteen patients had at least 1 TEAE of opioid withdrawal (Table 2). These included 12 patients in the naldemedine $0.2 \mathrm{mg}$ group $(1.0 \%, 12 / 1163)$ and 7 patients in the placebo group $(0.6 \%, 7 / 1165)$. The proportion of patients experiencing opioid withdrawal was $1.1 \%$ or less across RI subgroups.

\section{Efficacy}

The intent-to-treat population included 1095 patients from the COMPOSE-1 and COMPOSE-2 studies. Overall, a significantly greater proportion of patients in the naldemedine $0.2 \mathrm{mg}$ group were responders than in the placebo group: $50.1 \%$ vs $34.1 \%$, respectively $(P<0.0001$; difference in proportions [95\% CI]: $16.0 \%[10.2,21.8]$; Figure 3$)$. The proportions of responders were also significantly (lower limit of $95 \% \mathrm{CI}>0$ ) greater in the naldemedine group than the placebo group for all RI subgroups, with rates comparable to 
Table 2 Summary of Treatment-Emergent Adverse Events by eGFR at Baseline (Safety Population)

\begin{tabular}{|c|c|c|}
\hline & \multicolumn{2}{|c|}{$\begin{array}{l}\text { COMPOSE-I/COMPOSE-2/ } \\
\text { COMPOSE-3 }\end{array}$} \\
\hline & $\begin{array}{l}\text { Naldemedine } \\
0.2 \mathrm{mg} / \mathrm{day}, \% \\
(\mathrm{n} / \mathrm{N})\end{array}$ & $\begin{array}{l}\text { Placebo, \% } \\
(\mathrm{n} / \mathrm{N})\end{array}$ \\
\hline \multicolumn{3}{|l|}{ Any TEAE } \\
\hline Overall & $47.1(548 / 1 / 163)$ & $45.6(53 \mathrm{l} / \mathrm{I} / 65)$ \\
\hline$\geq 90 \mathrm{~mL} / \mathrm{min} / 1.73 \mathrm{~m}^{2}$ (normal) & $44.6(194 / 435)$ & $43.6(202 / 463)$ \\
\hline$\geq 60$ to $<90 \mathrm{~mL} / \mathrm{min} / \mathrm{l} .73 \mathrm{~m}^{2}$ (mild RI) & $49.0(291 / 594)$ & $44.7(256 / 573)$ \\
\hline$\geq 30$ to $<60 \mathrm{~mL} / \mathrm{min} / \mathrm{l} .73 \mathrm{~m}^{2}$ (moderate $\mathrm{RI}$ ) & $46.6(62 / 133)$ & $55.9(71 / 127)$ \\
\hline \multicolumn{3}{|l|}{ TEAEs of GI Disorders SOC } \\
\hline Overall & $21.8(253 / 1163)$ & $13.8(161 / / 165)$ \\
\hline$\geq 90 \mathrm{~mL} / \mathrm{min} / 1.73 \mathrm{~m}^{2}$ (normal) & $21.6(94 / 435)$ & $12.5(58 / 463)$ \\
\hline$\geq 60$ to $<90 \mathrm{~mL} / \mathrm{min} / 1.73 \mathrm{~m}^{2}$ (mild RI) & $22.6(134 / 594)$ & $14.7(84 / 573)$ \\
\hline$\geq 30$ to $<60 \mathrm{~mL} / \mathrm{min} / 1.73 \mathrm{~m}^{2}$ (moderate RI) & $18.0(24 / 133)$ & $14.2(18 / 127)$ \\
\hline \multicolumn{3}{|l|}{ TEAEs of Opioid Withdrawal } \\
\hline Overall & & \\
\hline$\geq 90 \mathrm{~mL} / \mathrm{min} / 1.73 \mathrm{~m}^{2}$ (normal) & I.I (5/435) & $0.4(2 / 463)$ \\
\hline$\geq 60$ to $<90 \mathrm{~mL} / \mathrm{min} / \mathrm{l} .73 \mathrm{~m}^{2}$ (mild RI) & $1.0(6 / 594)$ & $0.9(5 / 573)$ \\
\hline$\geq 30$ to $<60 \mathrm{~mL} / \mathrm{min} / 1.73 \mathrm{~m}^{2}$ (moderate RI) & $0.8(1 / 133)$ & 0 \\
\hline
\end{tabular}

Abbreviations: eGFR, estimated glomerular filtration rate; GI, gastrointestinal; RI, renal impairment; SOC, System Organ Class; TEAE, treatment-emergent adverse event.

that of the overall population. Proportions of responders were $52.0 \%$ and $39.3 \%$ (difference in proportions $[95 \% \mathrm{CI}]$ : $12.8 \%[3.2,22.3])$ with normal renal function, $48.3 \%$ and $30.3 \%$ in the mild RI subgroup $(18.0 \%[10.1,26.0])$, and $52.5 \%$ and $31.7 \%$ in the moderate RI subgroup (20.2\% [2.6, $37.8]$ ), for the naldemedine $0.2 \mathrm{mg}$ and placebo groups, respectively (Figures 3 and 4).

\section{Discussion}

This integrated analysis of patients with chronic noncancer pain and OIC enrolled in the COMPOSE-1, COMPOSE-2, and COMPOSE-3 clinical studies found no differences in the safety or efficacy of naldemedine in patients with varying degrees of renal function; specifically, normal function, mild impairment, and moderate impairment. Naldemedine $0.2 \mathrm{mg}$ treatment once daily was generally well tolerated compared with placebo for up to 12 weeks, regardless of renal function. The proportion of responders was greater in the naldemedine $0.2 \mathrm{mg}$ group versus the placebo group in the overall population, as well as across all renal function subgroups; responder rates were similar regardless of RI subgroup.

The incidence of overall TEAEs and TEAEs in GI Disorders SOC was similar in the overall safety population, in patients with normal renal function, and in those with mild or moderate RI. GI-related TEAEs occurred more frequently in the naldemedine group compared with the placebo group in the overall safety population and in all renal subgroups. The increased incidence of GI-related TEAEs is consistent with the mechanism of action of naldemedine, which reverses the effects of opioids on $\mu$-opioid receptors in the GI tract. ${ }^{5,8}$ As RI can potentially alter the bioavailability of drugs, dosage adjustments are often necessary to minimize the risk of adverse events. ${ }^{12}$ There are currently 3 PAMORAs approved in the US for treatment of OIC in patients with chronic non-cancer pain: naldemedine, naloxegol, and methylnaltrexone. ${ }^{5,13,14}$ Of these, naldemedine is the only one not requiring dose adjustment in patients with moderate or severe RI. ${ }^{5,13,14}$

Pharmacokinetic studies of naldemedine have found no differences in drug exposure among patients with mild, moderate, severe RI, end-stage renal disease, and normal kidney function. ${ }^{5}$ The data from this integrated analysis further support these findings, showing a consistent safety and efficacy profile of naldemedine in patients with varying degrees of renal function. Further, the incidence of TEAEs of opioid withdrawal was low and comparable between the naldemedine (range, $0 \%$ to $1.1 \%$ ) and placebo groups (range, $0 \%$ to $0.9 \%$ ). In contrast, pharmacokinetic studies of naloxegol and methylnaltrexone found increased drug exposure in patients with RI of varying severity as compared with patients without kidney disease. ${ }^{13,14}$ Consequently, dose reductions of naloxegol and methylnaltrexone are recommended for patients with moderate or severe RI. ${ }^{13,14}$

The main limitation of this analysis is that it is a post hoc subgroup analysis. However, the integrated safety population for this analysis $(\mathrm{n}=2328)$, which includes patients across the COMPOSE-1, COMPOSE-2, and COMPOSE-3 clinical studies, provides a large sample size and a robust data set for comparison of safety and tolerability in the overall population versus patients with varying degrees of renal function. Although the sample size for the intent-to-treat population from COMPOSE-1 and COMPOSE-2 was smaller (overall, $\mathrm{n}=1095$ ), the results across RI subgroups were consistent with the overall population. Data for patients with severe RI are not presented due to the low sample size ( $\mathrm{n}=3$ in the safety population and $\mathrm{n}=0$ in the intent-to-treat population), and as such, the results of this study cannot be extrapolated to these patients.

\section{Conclusion}

In conclusion, data from this integrated analysis confirm that naldemedine dose adjustments are not needed in 
NAL $0.2 \mathrm{mg} \quad$ Placebo
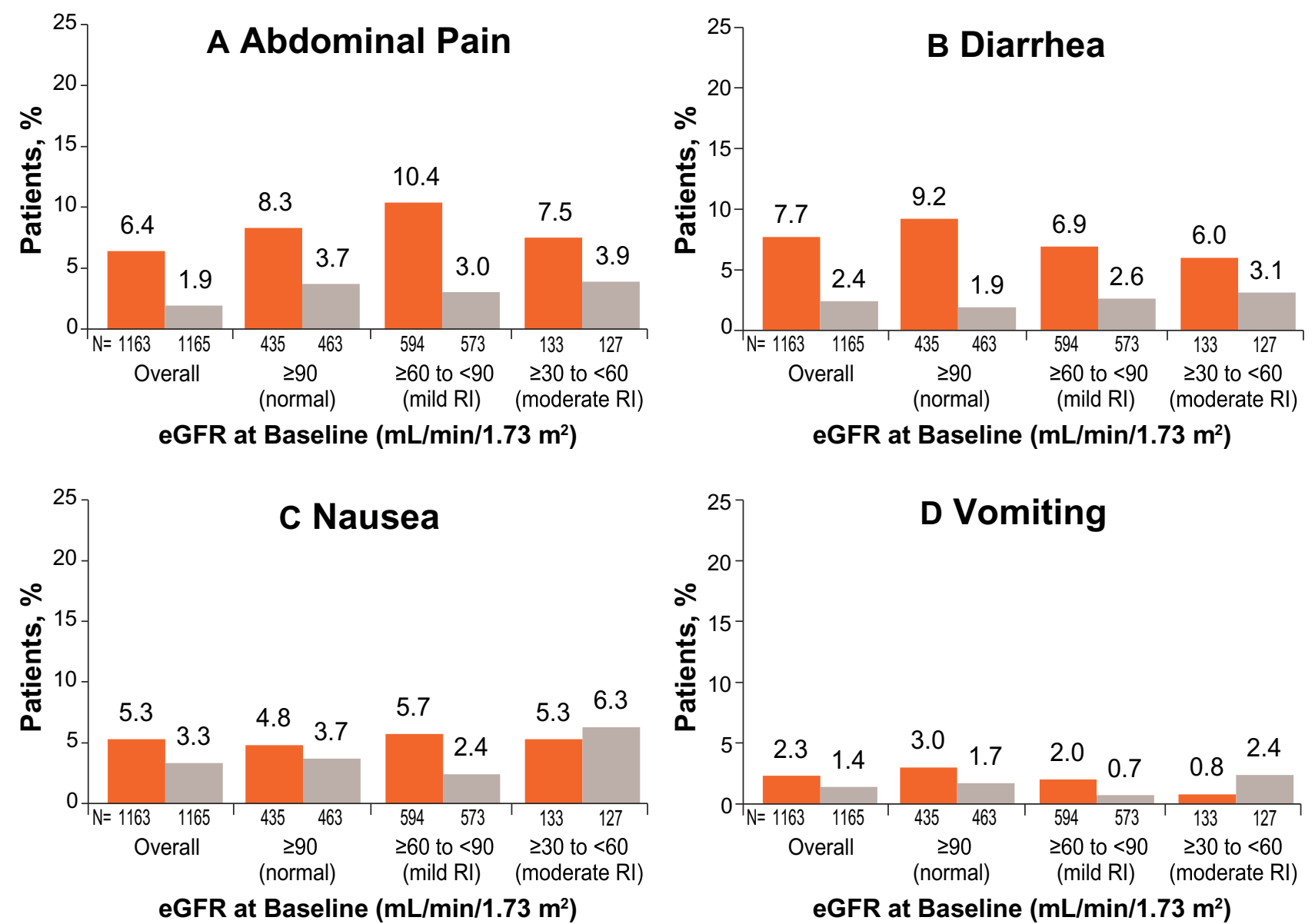

Figure 2 Incidence of abdominal pain (A), diarrhea (B), nausea (C), and vomiting (D) by eGFR at baseline (COMPOSE-I/COMPOSE-2/COMPOSE-3 safety population). Abbreviations: eGFR, estimated glomerular filtration rate; NAL, naldemedine, RI, renal impairment.

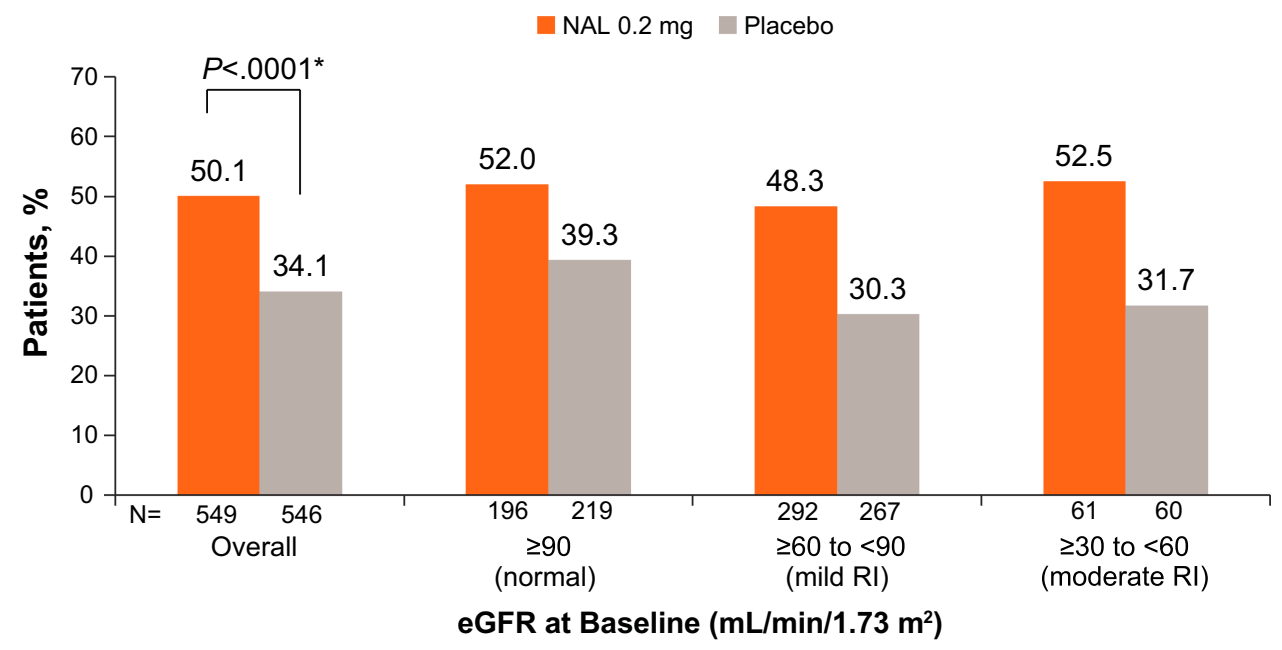

Figure 3 Proportion of responders by eGFR at baseline (COMPOSE-I/COMPOSE-2 intent-to-treat population). *P value for the overall population calculated by CochranMantel-Haenszel test; no statistical analyses were performed for subgroup comparisons.

Abbreviations: eGFR, estimated glomerular filtration rate; NAL, naldemedine, RI, renal impairment. 


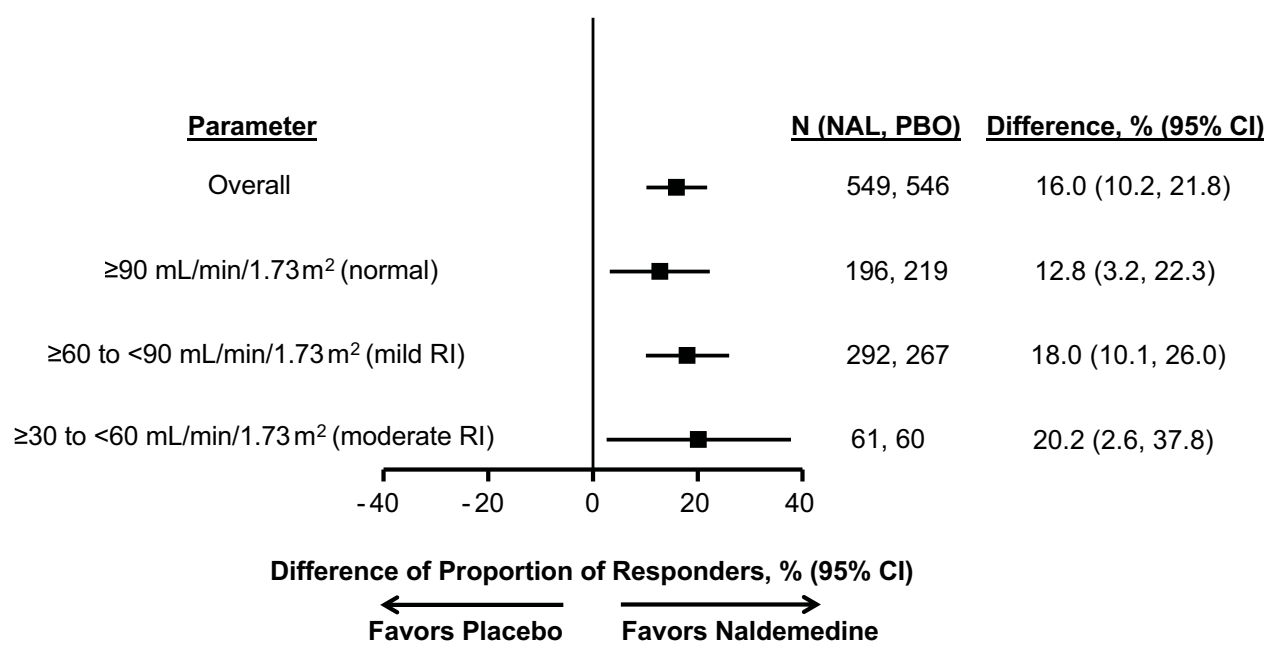

Figure 4 Difference of proportion of responders by eGFR at baseline (COMPOSE-I/COMPOSE-2 intent-to-treat population).

Abbreviations: $\mathrm{Cl}$, confidence interval; eGFR, estimated glomerular filtration rate; NAL, naldemedine; PBO, placebo; RI, renal impairment.

patients with mild or moderate RI. The results of this study also support the consistent safety and efficacy of naldemedine in the treatment of OIC.

\section{Abbreviations}

AE, adverse event; BMI, body mass index; eGFR, estimated glomerular filtration rate; GI, gastrointestinal; MED, morphine equivalent dose; OIC, opioid-induced constipation; PAMORA, peripherally acting $\mu$-opioid receptor antagonist; R, randomization; RI, renal impairment; SBM, spontaneous bowel movement; SD, standard deviation; SOC, System Organ Class; TEAE, treatmentemergent adverse event; US, United States.

\section{Data Sharing Statement}

All data generated or analyzed during this study are included in this published article.

\section{Acknowledgments}

Editorial and writing support was provided by Bina Patel, PharmD, of Peloton Advantage, LLC, an OPEN Health company, and funded by Shionogi Inc.

\section{Funding}

These studies were sponsored by Shionogi Inc., Florham Park, NJ. BDSI owns full rights to commercialize Symproic $^{\circledR}$ (naldemedine) tablets $0.2 \mathrm{mg}$ in the US for opioid-induced constipation.

\section{Disclosure}

LR Webster affiliated with PRA Health Sciences reports consultation and/or advisory board as well as travel expenses from BDSI, Ensysce, Inspirion, Alcobra, Bonti, Charleston Laboratories, Daiichi Sankyo, Depomed, Egalet, Elysium, Indivior, Insys, Kempharm, Mallinckrodt, Neurana, Pain Therapeutics, Pernix, Pfizer, Salix, Shionogi, Teva, and Trevena. He is also a consultant for Merck, Trevi, Vallon, and Vector. ME Hale affiliated with Gold Coast Research LLC was a consultant to and a principal investigator for Shionogi Inc. and received a stipend for review of the clinical study report. T Yamada is an employee of Shionogi Inc. who may or may not own stock options. JE Wild affiliated with Upstate Clinical Research Associates, received a stipend from Shionogi Inc. for review of the clinical study report. The authors report no other conflicts of interest in this work.

\section{References}

1. Noori SA, Aiyer R, Yu J, White RS, Mehta N, Gulati A. Nonopioid versus opioid agents for chronic neuropathic pain, rheumatoid arthritis pain, cancer pain and low back pain. Pain Manag. 2019;9(2):205-216. doi:10.2217/pmt-2018-0052

2. Camilleri M, Drossman DA, Becker G, Webster LR, Davies AN, Mawe GM. Emerging treatments in neurogastroenterology: a multidisciplinary working group consensus statement on opioid-induced constipation. Neurogastroenterol Motil. 2014;26 (10):1386-1395. doi:10.1111/nmo.2014.26.issue-10

3. Coyne KS, Margolis MK, Yeomans K, et al. Opioid-induced constipation among patients with chronic noncancer pain in the United States, Canada, Germany, and the United Kingdom: laxative use, response, and symptom burden over time. Pain Med. 2015;16(8):1551-1565. doi:10.1111/pme.12724 
4. Gupta S, Patel H, Scopel J, Mody RR. Impact of constipation on opioid therapy management among long-term opioid users, based on a patient survey. J Opioid Manag. 2015;11(4):325-338. doi:10.5055/ jom.2015.0282

5. Symproic [Package Insert]. Florham Park, NJ: Shionogi Inc.; 2018.

6. Symproic ${ }^{\circledR}$ (naldemedine) approved for the treatment of opioidinduced constipation in Japan [press release]; 2017. Available from: http://www.shionogi.eu/media/402717/e170330_2-symproic-

approved-for-treatment-of-oic-in-japan.pdf. Accessed January 17, 2020.

7. European Medicines Agency. Rizmoic (naldemedine); 2019. Available from: https://www.ema.europa.eu/en/medicines/human/ EPAR/rizmoic. Accessed January 17, 2020.

8. Hale M, Wild J, Reddy J, Yamada T, Arjona Ferreira JC. Naldemedine versus placebo for opioid-induced constipation (COMPOSE-1 and COMPOSE-2): two multicentre, phase 3, double-blind, randomised, parallel-group trials. Lancet Gastroenterol Hepatol. 2017;2(8):555-564. doi:10.1016/S2468-1253(17)30105-X
9. Webster LR, Nalamachu S, Morlion B, et al. Long-term use of naldemedine in the treatment of opioid-induced constipation in patients with chronic non-cancer pain: a randomized, double-blind, placebo-controlled phase 3 study. Pain. 2018;159(5):987-994. doi:10.1097/j.pain.0000000000001174

10. United States Renal Data System. 2018 annual data report highlights. 2018. Available from: https:/www.usrds.org/adrhighlights.aspx. Accessed February 7, 2020.

11. Munar MY, Singh H. Drug dosing adjustments in patients with chronic kidney disease. Am Fam Physician. 2007;75(10):1487-1496.

12. Smith BS, Yogaratnam D, Levasseur-Franklin KE, Forni A, Fong J. Introduction to drug pharmacokinetics in the critically ill patient. Chest. 2012;141(5):1327-1336. doi:10.1378/chest.11-1396

13. Movantik [Package Insert]. Wilmington, DE: AstraZeneca Pharmaceuticals; 2018.

14. Relistor [Package Insert]. Bridgewater, NJ: Salix Pharmaceuticals; 2018.

\section{Publish your work in this journal}

The Journal of Pain Research is an international, peer reviewed, open access, online journal that welcomes laboratory and clinical findings in the fields of pain research and the prevention and management of pain. Original research, reviews, symposium reports, hypothesis formation and commentaries are all considered for publication. The manuscript management system is completely online and includes a very quick and fair peer-review system, which is all easy to use. Visit http:// www.dovepress.com/testimonials.php to read real quotes from published authors. 